\title{
PROCEDIMENTOS METODOLÓGICOS PARA AVALIAÇÃO DE PRODUTOS EDUCACIONAIS: CONTRIBUIÇÕES PARA UM MESTRADO PROFISSIONAL DA ÁREA DE ENSINO DE HUMANIDADES
}

Dilza Côco

Instituto Federal do Espírito Santo, Brasil.dilzac@ifes.edu.br

\begin{abstract}
Resumo. $O$ artigo apresenta procedimentos metodológicos para avaliação de produtos educacionais oriundos de pesquisas elaboradas no Programa de Pós-Graduação em Ensino de Humanidades (PPGEH), do Instituto Federal do Espírito Santo (Ifes) - Brasil. Para este estudo adota como metodologia a pesquisa de levantamento, do tipo revisão sistemática, e toma como fonte de dados registros de materiais educativos publicados no sítio virtual Educapes. Visa compreender se a produção técnica publicada pelo PPGEH atende aos indicadores de qualidade previstos nos critérios de avaliação nacional. Para isso, realiza análise geral das características dessas produções em termos de formato, temática, registro, e ano de publicação. Em seguida, desenvolve análises específicas de cinco materiais educativos que versam sobre educação na cidade, a partir dos seguintes critérios: validação obrigatória, utilização nos sistemas de educação, registro do produto e acesso livre. Conclui que os materiais educativos do PPGEH contemplam em seu processo de produção e divulgação os indicadores de qualidade elegidos para avaliação nacional, mas são passiveis de aprimoramentos, especialmente quanto à diversificação de formatos e modos de registros da produção.
\end{abstract}

Palavras-chave: Mestrado Profissional; Materiais Educativos; Avaliação; Formação De Professores.

\section{EDUCATIONAL MATERIALS AND METHODOLOGICAL VALIDATION PROCESSES IN TEACHER EDUCATION}

\begin{abstract}
The article presents methodological procedures for evaluating educational products from research carried out in the Graduate Program in Teaching Humanities (PPGEH), from the Federal Institute of Espírito Santo (Ifes) - Brazil. For this study it adopts as a methodology the survey research, of the systematic review type, and takes as data source records of educational materials published on the Educapes website. It aims to understand whether the technical production published by PPGEH meets the quality indicators provided for in the national assessment criteria. For this, it performs a general analysis of the characteristics of these productions in terms of format, theme, registration, and year of publication. Then, it develops specific analyzes of five educational materials that deal with education in the city, based on the following criteria: mandatory validation, use in education systems, product registration and free access. It concludes that the educational materials of the PPGEH include, in their production and dissemination process, the quality indicators chosen for national assessment, but are subject to improvements, especially regarding the diversification of formats and modes of production records.
\end{abstract}

Keywords: Professional Master's Degree; Educational Materials; Evaluation; Teacher Training.

\section{INTRODUÇÃO}

No sistema de pós-graduação brasileiro, cujo principal órgão governamental de regulação e fomento é a Coordenação de Aperfeiçoamento de Pessoal de Nível Superior (Capes), está previsto a oferta de cursos de mestrado e doutorado profissional. Essa modalidade, em expansão no país (Rebeque, Osteman, \& Viseu, 2017) abarca diferentes áreas de 
conhecimento e se caracteriza, especialmente, por desenvolver pesquisas aplicada que gerem materiais educativos que possam ser amplamente divulgados e utilizados em vários contextos da sociedade (Osteman \& Resende, 2009). Na área de ensino, chamada de área 46 da Capes, foco das discussões deste artigo, a produção desses materiais educativos visam contribuir para a melhoria da qualidade da educação básica.

Documentos orientadores da Capes (2017) apontam a necessidade de avaliação dessa produção, denominada de produção técnica e elegem alguns indicadores de qualidade, tais como: validação obrigatória, registro do produto, utilização nos sistemas de educação e acesso livre. Desse modo, a produção dos materiais educativos para ser bem avaliada no quesito qualidade, precisa garantir todos esses elementos, sendo o processo de validação uma etapa importante a ser considerada no momento da elaboração, ou seja, ainda na fase do desenvolvimento da pesquisa (Leite, 2019). Para atender a esse indicador de qualidade é preciso que o material educativo seja utilizado em uma situação real ou de natureza experimental, mesmo que em pequena escala, e que privilegie a interação com o público alvo. É importante destacar, que os demais indicadores previstos para avaliação estão relacionados ao período posterior à produção. Assim, nesse texto iremos privilegiar discussões específicas sobre esses indicadores de qualidade que orientam a avaliação da produção técnica publicada em mestrados profissionais.

Cabe realçar que a produção técnica é composta por diferentes produtos educacionais, ou também denominadas de materiais educativos. Estes podem ser elaborados em diversos tipos e formatos. No documento da área 46 , encontramos especificações que informam que os materiais educativos podem ser:

(...) mídias educacionais; protótipos educacionais e materiais para atividades experimentais; propostas de ensino; material textual; materiais interativos; atividades de extensão e desenvolvimento de aplicativos. Todos os demais produtos serão contabilizados em relação ao número total, sem pontuação, exceto as seguintes atividades que receberão pontuação fixa: editoria, posfácio, prefácio, editorial, tradução de obras, patentes, organização de eventos, livros paradidáticos ou didáticos e artigos em revistas de divulgação científica (Capes, 2017, p. 14).

Esse extrato evidencia que os programas possuem liberdade para poder elaborar e criar materiais educativos diversos. Contudo, a variedade de tipos e formatos também gera desafios para os autores, como o custo de produção, as possibilidades de divulgação e testagem junto ao público alvo, a forma de registro de direito autoral dos produtos, a equipe 
técnica com conhecimentos e tecnologia que subsidiam a formulação gráfica e de edição dos recursos, dentre outros aspectos. Assim, algumas questões podem ser levantadas: qual o formato mais recorrente dos materiais educativos da área de ensino? De que modo essas produções são validadas? Como ocorre a participação do público alvo? Qual(is) estratégia(s) metodológica(s) é/são utilizada(s) no processo de avaliação? Como avaliar o potencial de utilização desses materiais? Essas produções atendem aos critérios de qualidade da Capes?

Essas questões são amplas e requerem um diálogo mais próximo com os dados. Assim, realizamos uma busca na base de dados virtual denominada de Educapes. Essa base foi criada e disponibilizada pela Capes para público em geral como estratégia ou ferramenta que reúne, divulga e disponibiliza o conjunto de objetos educacionais em formato digital, como as produções técnicas de todos os programas de pós-graduação reconhecidos e aprovados no Brasil. Esse levantamento, processado em 20 de fevereiro de 2020, apontou que o acervo do portal Educapes apresentava, na data da consulta, 16.809 registros. Quando refinamos a busca no sítio virtual pelo descritor "tipo de arquivo", as opções encontradas com maior número de registros foram, respectivamente, no formato de livro digital, que apresentou 8.711 ocorrências, vídeo com 2.115 ocorrências e texto com 1.358 ocorrências.

Esses dados revelam um grande número de produções, porém conhecer o quantitativo de registros não é suficiente para saber as motivações que levaram os autores a essas escolhas e nem muito menos sobre o processo metodológico de elaboração e avaliação dos recursos. Assim, para proceder uma análise mais detalhada optamos por explorar recorte de dados e considerar as produções de um programa de pós-graduação específico, vinculado à área de ensino de Humanidades, o Programa de Pós-Graduação em Ensino de Humanidades (PPGEH) inserido no Instituto Federal de Educação (Ifes). A escolha por esse programa deve-se ao fato da autora desse texto atuar como docente da equipe e ministrar disciplina sobre a produção de materiais educativos. Nessa disciplina, contempla-se discussões a respeito de fundamentos da produção dos conteúdos didáticos, perspectivas conceituais como as sugeridas por Kaplún (2002) e Ruiz (2014), recursos gráficos e estéticos, linguagem e metodologia de validação junto ao público alvo (Leite, 2019), dentre outros elementos. 
Dadas essas relações com o programa e a necessidade de conhecer as características de sua produção técnica, tendo em vista as demandas postas pela avaliação da Capes, que irá considerar dados do quadriênio 2017-2020, sistematizamos uma revisão sistemática das publicações de materiais educativos na base Educapes, no período entre 2017-2019. Cabe realçar que não incluímos registros de 2020, devido os dados estarem em consolidação, indicando a necessidade de complementações posteriores. Assim, o mapeamento do conjunto das produções do PPGEH apresentados nesse artigo tem como objetivo apresentar procedimentos metodológicos que subsidiem análises sobre as características das publicações como modo de verificar se atendem aos indicadores de qualidade exigidos pela Capes. Explorar esse objetivo torna-se importante para que o programa possa entender o perfil de suas publicações e direcionar novos investimentos técnicos e conceituais na busca pela melhoria da qualidade das produções e, consequentemente, contribuir para a educação básica brasileira.

Com esse propósito de discussão, organizamos esse artigo em quatro partes, incluindo essa introdução e as considerações finais. Na seção que segue, exibimos levantamento das produções de materiais educativos do PPGEH, a fim de expor um panorama geral das produções realizadas, entender as principais características dos recursos e desafios a serem superados no processo de elaboração. Na sequência, apresentamos análises mais detalhadas sobre o processo de elaboração de materiais educativos, desenvolvidos por um grupo de pesquisa, o Grupo de estudos e pesquisa educação na cidade e Humanidades (Gepech), que privilegia a temática educação na cidade. Essas análises têm por objetivo evidenciar dados mais específicos sobre os indicadores utilizados na avaliação da qualidade dos materiais educativos como validação obrigatória, acesso livre, registro e utilização/alcance dos materiais desenvolvidos pelo Gepech, na área de formação de professores. Ao compartilharmos esses procedimentos metodológicos de análises temos a expectativa de dar visibilidade às pesquisas realizadas pelo grupo, pontuar necessidades de novos investimentos que podem aprimorar a qualidade da produção, além de trazer uma possibilidade analítica que pode servir de inspiração para aqueles que dela necessitarem.

\section{MATERIAIS EDUCATIVOS DO PPGEH: UM PANORAMA GERAL DOS DADOS}

Explorar dados sobre materiais educativos oriundos de pesquisas do PPGEH requer uma certa contextualização. 
A primeira é que se trata de uma produção embrionária e, por isso, deve ser entendida como passível de aprimoramentos constantes. Utilizamos o termo embrionária porque é fruto de um programa de mestrado profissional jovem, criado em 2016, no contexto do Ifes, que reúne professores de diferentes áreas de conhecimento (Geografia, Letras, Arte, Filosofia, História, Pedagogia, Sociologia etc.).

A segunda especificidade, é que a produção desse programa será submetida pela primeira vez à avaliação nacional realizada pela Capes, e pode ser analisada a partir de duas linhas de pesquisa deste mestrado, a saber: Práticas de Ensino e Formação de Professores.

Em termos gerais, em consulta aos dados da plataforma Educapes, realizada no dia 20 de fevereiro de 2020, encontramos registros de 35 produções acadêmicas, sendo que 5 produções foram publicadas em 2017, 13 em 2018 e 17 em 2019. Portanto, uma produção crescente. Dessas, identificamos que 4 registros não disponibilizavam o arquivo do material educativo no sítio virtual, apenas informava o título e autoria da fonte. Dentre os demais 31 registros, uma proposta foi configurada na forma de vídeo e as outras 30 pesquisas foram materializadas na forma de livreto ou E-book.

Em nossa análise, vamos nos deter apenas à essa última categoria, chamada material textual, por se referir a opção mais utilizada pelos mestrandos do PPGEH. Por meio da leitura de todos os títulos e da seção de apresentação dos produtos educacionais, foi possível apreender elementos de identificação, como a informação de que 18 produtos educacionais estavam vinculados a práticas pedagógicas e 12 relacionados à ação de formação de professores.

Para explorar esse acervo de fontes, tomamos como referência os princípios metodológicos da pesquisa de revisão sistemática (Vosgerau \& Romanowski, 2014; Minayo, 2012; Côco, 2019) que permitem olhar retrospectivamente para o conjunto das produções de uma determinada área e elaborar sínteses que evidenciem potencialidades, mas que também revelem regiões de sombras que merecem novos investimentos e tratamentos metodológicos.

Nessa vertente, investigamos os materiais educativos do mestrado em ensino de Humanidades com o intuito de apreender os temas estudados, o público alvo, as formas de registro e os formatos. 
Em relação ao primeiro grupo, os de Práticas Pedagógicas, sintetizamos os dados no Quadro 1:

Quadro 1: Materiais educativos da linha de Práticas Pedagógicas do PPGEH (2017-2019)

\begin{tabular}{|c|c|c|c|c|c|}
\hline $\begin{array}{c}\text { Ano de } \\
\text { publicação }\end{array}$ & Temática & $\begin{array}{c}\text { Público alvo/etapa de } \\
\text { ensino }\end{array}$ & $\begin{array}{l}\text { Local de } \\
\text { Validação }\end{array}$ & $\begin{array}{l}\text { Material } \\
\text { educativo }\end{array}$ & $\begin{array}{l}\text { Forma } \\
\text { de } \\
\text { registr } \\
0\end{array}$ \\
\hline \multirow{5}{*}{2017} & $\begin{array}{l}\text { P1) Educação } \\
\text { ambiental }\end{array}$ & $\begin{array}{l}\text { Ensino } \\
\text { Fundamental II }\end{array}$ & Vitória & $\begin{array}{l}\text { Jogo } \\
\text { E-book }\end{array}$ & $\begin{array}{l}- \\
\text { ISBN }\end{array}$ \\
\hline & $\begin{array}{l}\text { P2) Educação } \\
\text { Patrimonial }\end{array}$ & $\begin{array}{l}\text { Ensino } \\
\text { Fundamental II }\end{array}$ & $\begin{array}{l}\text { Proposta não } \\
\text { aplicada }\end{array}$ & $\begin{array}{l}\text { Sequência } \\
\text { didática - } \\
\text { Livreto }\end{array}$ & $\begin{array}{l}\text { Sem } \\
\text { registro }\end{array}$ \\
\hline & $\begin{array}{l}\text { P3) Ensino de filosofia } \\
\text { e movimentos sociais }\end{array}$ & $\begin{array}{l}\text { Ensino Médio integrado a } \\
\text { educação profissional }\end{array}$ & Ifes-Linhares & E-book & ISBN \\
\hline & $\begin{array}{l}\text { P4) Negro e } \\
\text { resistência }\end{array}$ & Ensino Fundamental II & Cariacica & E-book & ISBN \\
\hline & $\begin{array}{l}\text { P5)História do Espírito } \\
\text { Santo }\end{array}$ & Ensino Fundamental II & $\begin{array}{l}\text { Proposta não } \\
\text { aplicada }\end{array}$ & E-book & ISBN \\
\hline \multirow{6}{*}{2018} & $\begin{array}{l}\text { P6) Grêmio estudantil } \\
\text { e participação }\end{array}$ & Ensino Fundamental II & Serra & E-book & ISBN \\
\hline & $\begin{array}{l}\text { P7) Literatura } \\
\text { capixaba }\end{array}$ & Ensino médio & Serra & Paradidático & ISBN \\
\hline & $\begin{array}{l}\text { P8) Autismo e } \\
\text { linguagem }\end{array}$ & Ensino Fundamental II & Vitória & E-book & ISBN \\
\hline & $\begin{array}{l}\text { P9) História do } \\
\text { Espírito Santo }\end{array}$ & Ensino Fundamental I e II & $\begin{array}{l}\text { Proposta não } \\
\text { aplicada }\end{array}$ & E-book & ISBN \\
\hline & $\begin{array}{l}\text { P10) História local e } \\
\text { memória }\end{array}$ & Ensino Fundamental II & Vitória & $\begin{array}{l}\text { Site } \\
\text { E-book }\end{array}$ & $\begin{array}{l}-- \\
\text { ISBN }\end{array}$ \\
\hline & $\begin{array}{l}\text { P11) Ambiguidade e } \\
\text { produção de sentidos } \\
\text { na Língua Portuguesa }\end{array}$ & Ensino médio & Cariacica & E-book & ISBN \\
\hline \multirow{7}{*}{2019} & $\begin{array}{l}\text { P12) Circuito cultural e } \\
\text { patrimônio }\end{array}$ & Ensino Fundamental II & Projeto social & Livreto & ISBN \\
\hline & $\begin{array}{l}\text { P13) Manifestação } \\
\text { cultural - congo }\end{array}$ & Ensino Fundamental II & Cariacica & Paradidático & ISBN \\
\hline & $\begin{array}{l}\text { P14) Educação } \\
\text { ambiental e aula de } \\
\text { campo }\end{array}$ & Ensino médio & Serra & Livreto & ISBN \\
\hline & $\begin{array}{l}\text { P15) Educação } \\
\text { ambiental }\end{array}$ & Ensino Fundamental II & Serra & E-book & ISBN \\
\hline & $\begin{array}{l}\text { P16) Educação } \\
\text { ambiental e trilha }\end{array}$ & Ensino médio & Cariacica & Livreto & ISBN \\
\hline & $\begin{array}{l}\mathrm{P} 17) \text { Relações étnico } \\
\text { raciais }\end{array}$ & Ensino Fundamental I & Serra & Livro & $\begin{array}{l}\text { Sem } \\
\text { registro }\end{array}$ \\
\hline & $\begin{array}{l}\text { P18) Processo de } \\
\text { Colonização Italiana } \\
\text { no ES }\end{array}$ & Ensino Fundamental II & $\begin{array}{l}\text { Marechal } \\
\text { Floriano }\end{array}$ & E-book & ISBN \\
\hline
\end{tabular}

Fonte: Educapes. Elaboração da autora.

O dados do Quadro 1 mostram que a etapa do ensino fundamental II foi a mais focalizada nas propostas dos materiais educativos, com 13 ocorrências, enquanto que temáticas do ensino médio foram abordadas em 5 produtos (P3, P7, P11, P14, P16), e o ensino fundamental I foi objeto de atenção de apenas uma pesquisa (P17), o que pode ser entendido com um campo que merece maior investimento do PPGEH. 
Em relação às temáticas, notamos uma diversidade de assuntos/conteúdos, ganhando destaque a educação ambiental e a história do Espírito Santo. Sobre a validação dos produtos educacionais, quase todos foram experimentados com estudantes da rede pública de ensino, localizada na região metropolitana da cidade de Vitória-ES, Brasil.

Apenas duas cidades do interior do Estado, como Marechal Floriano e Linhares, foram lócus das pesquisas (P3, P18), fato que mostra, de certo modo, a baixa abrangência do PPGEH. A forma de registro dos materiais educativos analisados também expressa recorrências e está em consonância com o tipo de produto, classificado pelos documentos da Capes como material textual.

Assim, o International Standard Book Number (ISBN) constitui a forma de registro oficial e, no caso das pesquisas do PPGEH, esse aspecto é bastante favorecido, pois o lfes conta com um serviço de biblioteconomia bem estruturado.

Os dados ainda informam que algumas pesquisas desenvolvem mais de um produto educacional, como foi o caso da pesquisa 1 que elaborou, além de um e-book também sistematizou um jogo sobre educação ambiental.

Em outro caso a pesquisa 10, durante o trabalho de campo produziu um site que divulgava uma série de trabalhos sobre memória de uma comunidade, além de publicar um e-book, ao final.

Porém, cabe ressaltar que essas produções elaboradas durante o processo da pesquisa não receberam nenhum tratamento em relação aos registros autorais, fato que merece investimentos e atenção do corpo discente e docente do programa.

O segundo grupo de fontes de dados discutidos nesse artigo está relacionado à linha de formação de professores, conforme mostra o Quadro 2. 
Quadro 2: Materiais educativos da linha de Formação de Professores do PPGEH (2017-2019)

\begin{tabular}{|c|c|c|c|c|c|}
\hline $\begin{array}{c}\text { Ano de } \\
\text { publicação }\end{array}$ & Tema & $\begin{array}{c}\text { Público alvo/etapa de } \\
\text { ensino }\end{array}$ & $\begin{array}{l}\text { Local de } \\
\text { validação }\end{array}$ & Produto & $\begin{array}{c}\text { Forma } \\
\text { de } \\
\text { registro }\end{array}$ \\
\hline \multirow{6}{*}{2018} & $\begin{array}{l}\text { P1) Educação na } \\
\text { cidade e educação } \\
\text { infantil }\end{array}$ & $\begin{array}{l}\text { Professores da } \\
\text { educação infantil }\end{array}$ & Vitória & $\begin{array}{l}\text { Curso de } \\
\text { extensão } \\
\text { Ebook }\end{array}$ & ISBN \\
\hline & $\begin{array}{l}\text { P2) Educação na } \\
\text { cidade e a temática } \\
\text { afro-brasileira }\end{array}$ & $\begin{array}{l}\text { Ensino fundamental II - } \\
\text { EJA }\end{array}$ & Vitória & $\begin{array}{l}\text { Palestra } \\
\text { Ebook }\end{array}$ & ISBN \\
\hline & $\begin{array}{l}\text { P3) Educação na } \\
\text { cidade e educação } \\
\text { ambiental }\end{array}$ & $\begin{array}{l}\text { Professores do ensino } \\
\text { fundamental II e Médio }\end{array}$ & $\begin{array}{l}\text { Vitória } \\
\text { Serra } \\
\text { Cariacica } \\
\text { Vila Velha }\end{array}$ & $\begin{array}{l}\text { Cursos de } \\
\text { extensão } \\
\text { Ebook }\end{array}$ & ISBN \\
\hline & $\begin{array}{l}\text { P4) Educação na } \\
\text { cidade e processo de } \\
\text { modernização de } \\
\text { Vitória }\end{array}$ & $\begin{array}{l}\text { Professores do ensino } \\
\text { fundamental II e Médio }\end{array}$ & $\begin{array}{l}\text { Vitória } \\
\text { Serra } \\
\text { Cariacica } \\
\text { Vila Velha }\end{array}$ & $\begin{array}{l}\text { Cursos de } \\
\text { extensão } \\
\text { Ebook }\end{array}$ & ISBN \\
\hline & $\begin{array}{l}\text { P5) Educação na } \\
\text { cidade e memória }\end{array}$ & $\begin{array}{l}\text { Professores do ensino } \\
\text { fundamental II e Médio }\end{array}$ & $\begin{array}{l}\text { Vitória } \\
\text { Serra } \\
\text { Cariacica } \\
\text { Vila Velha }\end{array}$ & $\begin{array}{l}\text { Cursos de } \\
\text { extensão } \\
\text { Ebook }\end{array}$ & -- \\
\hline & $\begin{array}{l}\text { P6) Literatura e } \\
\text { alfabetização }\end{array}$ & $\begin{array}{l}\text { Professores dos anos } \\
\text { inicias }\end{array}$ & Vila Velha & Ebook & ISBN \\
\hline \multirow{6}{*}{2019} & $\begin{array}{l}\text { P7) Práticas de leitura } \\
\text { nos anos iniciais }\end{array}$ & $\begin{array}{l}\text { Professores dos anos } \\
\text { iniciais }\end{array}$ & Cariacica & $\begin{array}{l}\text { Curso de } \\
\text { extensão } \\
\text { Ebook }\end{array}$ & $\begin{array}{l}-- \\
\text { ISBN }\end{array}$ \\
\hline & $\begin{array}{l}\text { P8) Ensino de literatura } \\
\text { - Machado de Assis }\end{array}$ & $\begin{array}{l}\text { Professores do ensino } \\
\text { médio }\end{array}$ & $\begin{array}{l}\text { Cachoeiro do } \\
\text { Itapemirim }\end{array}$ & Ebook & ISBN \\
\hline & $\begin{array}{l}\text { P9) Arte e } \\
\text { simbolização na Ed. } \\
\text { Infantil }\end{array}$ & $\begin{array}{l}\text { Professores da } \\
\text { educação infantil }\end{array}$ & $\begin{array}{l}\text { Proposta não } \\
\text { aplicada }\end{array}$ & Livreto & ISBN \\
\hline & $\begin{array}{l}\text { P10) Colonização do } \\
\text { Espírito Santo }\end{array}$ & $\begin{array}{l}\text { Professores do Ensino } \\
\text { Fundamental II }\end{array}$ & Vila Velha & Ebook & ISBN \\
\hline & $\begin{array}{l}\text { P11) Tecnologias } \\
\text { digitais e educação } \\
\text { infantil }\end{array}$ & $\begin{array}{l}\text { Professores da } \\
\text { educação infantil }\end{array}$ & Serra & Ebook & ISBN \\
\hline & $\begin{array}{l}\text { P12) Ensino de } \\
\text { literatura - Mário de } \\
\text { Andrade }\end{array}$ & $\begin{array}{l}\text { Professores do ensino } \\
\text { médio }\end{array}$ & Cariacica & Ebook & ISBN \\
\hline
\end{tabular}

Fonte: Educapes. Elaboração da autora.

Os materiais educativos da linha de formação de professores (Quadro 2) foram publicados somente a partir de 2018 e oferecem proposições a todas as etapas da educação básica. Porém, nota-se que os professores do ensino fundamental II e do ensino médio constituíram o público alvo principal, presentes em 7 produções. A formação de profissionais da educação infantil foi atenção de outras três pesquisas (P1, P9 e P11) e dos nos anos iniciais apenas em duas (P6 e P7). Em relação às temáticas, encontramos duas pesquisas (P8 e P12) com foco no ensino da literatura e cinco pesquisas referentes ao tema educação na cidade (P1, P2, P3, P4, P5). Cabe destacar que esse tema foi o que reuniu o maior número de publicações e foi discutido em processos formativos com professores da Educação 
Infantil, Educação de Jovens e Adultos, Ensino Fundamental II e Ensino Médio. Considerando que essa temática assume um certo destaque no conjunto das produções da linha de formação de professores e, devido aos limites de extensão desse texto, iremos privilegiar análises mais específicas sobre esses cinco materiais educativos, buscando compreender se as características dos mesmos estão em consonância com os indicadores de qualidade da avaliação, preconizados em documentos da Capes (2017). Assim, na próxima seção, abordaremos mais detalhadamente dados sobre o processo de elaboração e validação desses materiais educativos, as formas de registros e divulgação, bem como dados sobre a inserção no contexto educacional. Os procedimentos metodológicos adotados para essa abordagem consistiram na leitura do conteúdo dos materiais educativos e levantamento de dados quantitativos sobre acesso de cada material educativo, obtidos nos registros da plataforma Educapes.

\section{MATERIAIS EDUCATIVOS DO GEPECH: UMA ANÁLISE A PARTIR DOS CRITÉRIOS DE AVALIAÇÃO DA CAPES}

Nessa seção, desenvolvemos análises mais detalhadas sobre a produção de materiais educativos publicados pelo PPGEH. Essas análises incidem nos materiais que privilegiaram a temática da educação na cidade, na linha de formação de professores, mais especificamente as produções de autoria de Fraga, Côco e Chisté (2018), Morais e Côco (2018), Frois e Della Fonte (2018), Pinheiro e Leite (2018), Pinto e Leite (2018). A escolha dessas fontes foi devida à temática concentrar o maior número de trabalhos no conjunto dos dados do PPGEH como já indicamos. É importante situar ainda que todas essas produções foram oriundas de pesquisas vinculadas ao Grupo de Estudos e Pesquisas em Educação na Cidade e Humanidades (Gepech). Esse grupo foi criado em 2016, e reúne professores, mestrandos e egressos do PPGEH, que desenvolvem diferentes ações de estudos e pesquisas observando três objetivos: 1) discutir relações entre a cidade e a educação a partir de áreas do conhecimento ligadas às humanidades; 2) planejar, executar e avaliar formações de professores da educação básica que contribuam com reflexões sobre os espaços da cidade; bem como 3) sistematizar materiais educativos que discutam e apresentem propostas relacionadas com a cidade. Esses objetivos apresentam conexões entre si e se materializam em ações de formação docente, apresentadas nos cinco materiais educativos analisados nesse artigo. Neles, entrevemos três modos distintos de interação, diálogo e parcerias com o público alvo. 
1) Confluência de interesses - o pesquisador apresenta proposta de pesquisa para uma escola específica que manifesta interesse no acolhimento da ação de estudo e de formação docente. Esse tipo de parceria pode ser observado no conteúdo do material educativo de Fraga, Côco e Chisté (2018) que apresenta dados sobre formação de professores da educação infantil relacionado ao potencial educativo da região de localização da escola. Nesse caso, o material educativo foi experimentado e validado com cinco professoras, por meio de encontros de estudos coletivos realizados na escola, organizados na forma de ação de extensão, com 60 horas de atividades.

2) Integração pesquisador e escola - o pesquisador insere-se no contexto escolar para conhecer o trabalho realizado e, a partir dele, contribui com proposições didático pedagógicas, como descrito no material educativo elaborado por Morais e Côco (2018). Tais proposições devem ser formuladas a partir de temas elegidos pela escola, e mobilizam o pesquisador a realizar estudos aprofundados para sistematizar uma proposta de trabalho a ser compartilhada com a equipe da escola. O material educativo de Morais e Côco (2018) revela esse movimento de diálogo, quando faz a proposta do material educativo sobre a temática afro-brasileira, que foi compartilhada e validada em encontro de formação com 25 profissionais de uma escola de educação de jovens e adultos (EJA).

3) Demanda social - por meio de chamada pública, um ou mais pesquisadores apresentam proposta de pesquisa e de formação. Os interessados se manifestam por iniciativas independentes, colaborando para a constituição de grupos heterogêneos de participantes. Essa forma de organização de parcerias e diálogos com os professores pode ser encontrada nas experiências formativas descritas nos materiais de Pinto e Leite (2018), Pinheiro e Leite (2018) e Frois e Della Fonte (2018). As propostas de trabalho pedagógico desses três materiais educativos foram discutidas em ação formativa, por meio de ação de extensão, envolvendo 18 professores do ensino fundamental II e ensino médio, que atuavam em diferentes escolas das redes públicas municipais e estadual de ensino.

Outra característica interessante do grupo era que os participantes lecionavam em diferentes áreas de conhecimento como Arte, Geografia, História, Língua Portuguesa, 
Sociologia entre outras, possibilitando assim diferentes olhares sobre a validação dos materiais educativos.

Essa validação ocorreu em encontros de estudos coletivos organizados por módulos. O primeiro módulo dedicou atenção às marcas e aos vestígios existentes no centro histórico de Vitória-ES, Brasil que possibilitou explorar conhecimentos relativos ao processo de modernização da cidade (Pinto \& Leite, 2018). O segundo módulo recorreu ao conceito de espaço-memória e contemplou discussões com base em transformações físicas e culturais promovidas na cidade a partir da criação de um parque municipal (Pinheiro \& Leite, 2018). O terceiro módulo explorou conhecimentos relacionados à fase da industrialização da cidade e o processo de modernização (Frois \& Della Fonte, 2018).

Essas três formas de interação e diálogo com o público alvo utilizadas na produção dos cinco materiais educativos, favoreceram o processo de validação e, consequentemente, contribuíram para divulgação e para a utilização dessa produção em termos locais. Desse modo, podemos inferir que os produtos educacionais publicados pelo PPGEH, com vinculações com o Gepech, atendem inicialmente a esses três indicadores de avaliação de qualidade previstos nos documentos da Capes, validação, utilização pelos sistemas de ensino e acesso.

Em termos de registros, identificamos que os cinco materiais analisados apresentaram o registro de ISBN, na categoria e-book.

Vale realçar que para superar essa dimensão local das pesquisas do PPGEH e do Gepech, e avançar na direção de atingir um público maior com o objetivo de atender com mais expressividade os indicadores de qualidade relacionados à divulgação e utilização pelos sistemas de ensino, os materiais educativos do PPPGEH foram/são disponibilizados no site institucional do programa (https://ppgeh.vitoria.ifes.edu.br/index.php/producao-academica) e no portal Educapes (https://educapes.capes.gov.br).

De modo complementar, os materiais produzidos em pesquisas coordenadas pelo Gepech também foram/são disponibilizados no site (https://gepech.wordpress.com/dissertacoes-emateriais-educativos/) do grupo de pesquisa.

Entendemos que esses vários canais de divulgação colaboram para consolidar outros dados de acesso e de apropriação dos materiais, registrados no portal Educapes. Em relação as 
fontes analisadas, o levantamento nos dados do portal Educapes, até o mês de fevereiro de 2020, mostram diferentes informações (Quadro 3).

Quadro 3 - Dados de acesso dos materiais educativos do Gepech no portal Educapes

\begin{tabular}{|c|c|c|c|c|}
\hline Material Educativo & Visualização & $\begin{array}{l}\text { Download } \\
\text { do } \\
\text { arquivo }\end{array}$ & $\begin{array}{l}\text { Origem do } \\
\text { acesso por } \\
\text { países }\end{array}$ & Origem do acesso por cidades \\
\hline $\begin{array}{l}\text { Fraga, Côco e } \\
\text { Chisté (2018) }\end{array}$ & 48 & 22 & 2 - Brasil, USA & $\begin{array}{l}8 \text { cidades } \\
\text { Vila Velha, Vitória, Guarapari, } \\
\text { Menlo Park, Piúma, Sumaré, São } \\
\text { Mateus }\end{array}$ \\
\hline $\begin{array}{l}\text { Morais e Côco } \\
(2018)\end{array}$ & 23 & 32 & 2 - Brasil, USA & $\begin{array}{l}10 \text { Cidades } \\
\text { Vila Velha, Vitória, Cariacica, } \\
\text { Florianópolis, Linhares, Natal, Rio } \\
\text { de Janeiro, Santa Maria, São } \\
\text { Mateus }\end{array}$ \\
\hline Pinto e Leite (2018) & 37 & 35 & $\begin{array}{l}3 \text { - Brasil, USA, } \\
\text { Reino Unido }\end{array}$ & $\begin{array}{l}10 \text { Cidades } \\
\text { Vila Velha, Vitória, Linhares, São } \\
\text { Mateus, Cariacica, Menlo Park, Rio } \\
\text { de Janeiro, Campinas, } \\
\text { Florianópolis, Juruaia }\end{array}$ \\
\hline $\begin{array}{l}\text { Pinheiro e Leite } \\
\text { (2018) }\end{array}$ & 36 & 274 & 2 - Brasil, USA & $\begin{array}{l}10 \text { Cidades } \\
\text { Vila Velha, Cariacica, Linhares, } \\
\text { Curitiba, Menlo Park, Piúma, Santa } \\
\text { Maria, São Mateus, Vitória, Belo } \\
\text { Horizonte }\end{array}$ \\
\hline $\begin{array}{l}\text { Frois e Della Fonte } \\
(2018)\end{array}$ & 40 & 40 & $\begin{array}{l}3 \text { - Brasil, USA, } \\
\text { Reino Unido }\end{array}$ & $\begin{array}{l}10 \text { Cidades } \\
\text { Vila Velha, Cariacica, Linhares, São } \\
\text { Mateus, Vitória, Asburn, } \\
\text { Florianópolis, Guarapari, Juazeiro } \\
\text { do Norte, Muzambinho. }\end{array}$ \\
\hline
\end{tabular}

Fonte: Portal Educapes. Elaboração da autora.

Os dados do Quadro 3 sinalizam que as estratégias de divulgação dos materiais educativos, por meio de ferramentas digitais, como o portal Educapes, possibilitam que diferentes públicos acessem e conheçam as propostas temáticas e as ações desenvolvidas pelo Gepech. Quando visualizamos os dados sobre as cidades, notamos que cidades do Espírito Santo foram as mais registradas nos dados de acesso, provavelmente pela localização geográfica do PPGEH e do Gepech. Porém, também notamos que o alcance dos materiais educativos rompem fronteiras e chegam em outros estados brasileiros como Natal/RN, Rio de Janeiro (RJ), Campinas (SP), Florianópolis (SC), Juazeiro do Norte (BA) e Belo Horizonte (MG). Além de romper fronteiras regionais, superam fronteiras nacionais, considerando os registros de cidades dos Estados Unidos da América, tais como Menlo Park e Ashburn. Com a exposição desses dados mais específicos dos materiais educativos da linha de Formação de Professores e vinculados ao Gepech, percebemos que as fontes atendem a todos os indicadores privilegiados pela avaliação da Capes, especialmente no sentido de permitir o acesso livre e amplo. Quanto a questão de utilização pelos sistemas públicos de ensino, os 
dados estatísticos do Educapes podem sugerir essa apropriação devido ao número de download dos arquivos, mas não é possível afirmar com precisão essa utilização. É importante lembrar que os indicadores de avaliação da qualidade dos materiais educativos, previstos em documentos orientadores da Capes, estão em processo de discussão para a composição de metodologias e instrumentos de aplicação nas avaliações anuais e do quadriênio 2017-2020. Nesse cenário, esta temática guarda possibilidades de discussões, de aprimoramentos e de novas compreensões.

\section{CONSIDERAÇÕES FINAIS}

Conforme apontado, este artigo teve como objetivo apresentar procedimentos metodológicos que subsidiem análises sobre as características das publicações como modo de verificar se atendem aos indicadores de qualidade exigidos pela Capes. Para tanto, evidenciamos com a exposição dos dados contribuições do princípios metodológicos da revisão sistemática de literatura para estruturar levantamento da produção técnica de um mestrado profissional, na área de ensino de Humanidades, o PPGEH. Esse levantamento tomou como base de dados os registros da plataforma Educapes e mostrou que o acervo de produções do programa contabilizava 35 publicações para o período 2017-2019. Cabe destacar que a realização de análises sobre esse recorte de dados torna-se importante na atualidade, devido as novas exigências avaliativas emanadas pela principal agência de regulação e fomento da pós-graduação do Brasil, a Capes. Com base em documentos orientadores, essa agência informa que um dos critérios da avaliação dos programas de pós-graduação é a qualidade da produção técnica. Essa qualidade deverá ser aferida a partir de indicadores que evidenciem que o produto passou por processos de validação, de preferência com o público alvo, que apresenta registro em bases reconhecidas, que demonstre utilização pelos sistemas de ensino e que seja disponibilizado de forma livre ao público em geral.

Diante dessas demandas conhecer as características do conjunto das publicações do programa PPGEH torna-se uma necessidade, para que docentes e discentes possam adotar ajustes no processo de elaboração de futuros materiais educativos, assim como aprimoramentos para alcançar uma melhor avaliação nesse critério de produção técnica. Assim, as análises evidenciaram que a produção do programa é marcada pela categoria de material textual, pois 30 materiais educativos adotaram o formato livreto ou e-book. 
Essa opção recorrente pode ser entendida, numa perspectiva positiva, pela maior facilidade no domínio da linguagem escrita por parte dos mestrandos e de acesso aos serviços de registro de autoria dos produtos, devido a estrutura de biblioteconomia oferecida pelo Ifes. Contudo, também pode significar limites e apontar necessidades de avanços sobre outras formas de registros, pois o PPGEH realizou uma série de ações de extensão, como foram os cursos de formação de professores, desenvolvidos pelas pesquisas do Gepech.

Além dessa modalidade de cursos, algumas outras pesquisas produziram jogo, site e vídeo, mas essa produção não recebeu nenhum tratamento quanto ao registro de autoria.

É possível inferir que tais produtos podem ser considerados subprodutos das pesquisas, ficando pouco visíveis para o público em geral, ganhando realce apenas as produções de livretos e e-book.

Em relação aos critérios de acesso livre, os dados mostraram que a disponibilização dos produtos na forma eletrônica, com realce para os recursos da plataforma Educapes que apresenta caráter agregador da produção nacional, constituiu uma estratégia importante de divulgação, atendendo plenamente ao exigido pelos indicadores da avaliação.

Os dados mais detalhados sobre esse processo de divulgação apontam a relevância das ferramentas digitais de publicação, pois mostram que esses canais possibilitam romper fronteiras locais e nacionais da produção, como demonstrado pelos dados das publicações sobre educação na cidade da área de formação de professores, vinculados ao Gepech. Contudo, o indicador sobre utilização dos produtos pelos sistemas de ensino ainda constitui um desafio a ser pensado, pois apenas os registros de download dos arquivos, apresentados nos dados estatísticos da plataforma Educapes, podem não garantir a efetividade dessa informação.

Assim, finalizamos esse texto com a compreensão de que a produção técnica do PPGEH está alinhada aos indicadores de qualidade instituídos pela avaliação da Capes.

Contudo, é preciso avançar nas estratégias metodológicas de apurar indicadores sobre as contribuições em termos de utilização dos recursos pelo público em geral. Inferimos ainda que as diretrizes da Capes para avaliação dos materiais educativos ainda irão estimular outros debates, abrindo novas frentes de estudos e pesquisas. 


\section{REFERÊNCIAS}

Côco, D. (2019). Revisão de literatura na área de ensino de Humanidade. Atas - Investigação qualitativa em $\begin{array}{llllll}\text { Educação, } & \text { v. } & 1, & \text { pp. } & \text { 427-447. } & \text { Recuperado }\end{array}$ https://proceedings.ciaiq.org/index.php/CIAIQ2019/article/view/2116/2047.

Capes. (2017). Relatório de avaliação da área de ensino. Brasil. Recuperado de https://capes.gov.br/images/stories/download/avaliacao/relatorios-finais-quadrienal-2017/20122017ENSINO-quadrienal.pdf.

Fraga, D., Côco, D., \& Chisté, P. S. (2018). Educação na cidade: diálogos entre educação infantil, cidade e patrimônio cultural. Vitória-ES, Brasil: Editora Ifes. Recuperado de https://educapes.capes.gov.br/handle/capes/552884.

Frois, I., \& Della Fonte, S. S. (2018). O entorno da Vale-SA na perspectiva da cidade educativa. Vitória-ES, Brasil: Editora Ifes. Recuperado de https://educapes.capes.gov.br/handle/capes/552906.

Kaplún, G. (2002). Contenidos, itinerarios y juegos: tres ejes para el análisis y la construcción de mensajes educativos. VI Congreso de ALAIC - Asociación Latinoamericana de Investigadores de la Comunicación Santa Cruz de la Sierra, Bolivia, junio 2002 - Grupo de Trabajo: Comunicación y Educación. 01-18.

Leite, P. S. C. (2019). Proposta de avaliação coletiva de materiais educativos em mestrados profissionais na área de ensino. Revista Campo Aberto, 38, 185-198.

Minayo, M. C. (2012). Análise qualitativa: teoria, passos e fidedignidade. Ciência \& Saúde Coletiva, 17 (3), 621 626.

Morais, E. R. V., \& Côco, D. (2018). Educação na cidade: diálogos possíveis para explorar a temática afrobrasileira. Vitória-ES, Brasil: Editora lfes. Recuperado de https://educapes.capes.gov.br/handle/capes/552963.

Ostermann, F., \& Rezende, F. (2009). Projetos de desenvolvimento e de pesquisa na Área de Ensino de Ciências e Matemática: uma reflexão sobre os mestrados profissionais. Caderno Brasileiro de Ensino de Física, Florianópolis, 26(1), 66-80. Recuperado de http://dx.doi.org/10.5007/2175-7941.2009v26n1p66.

Pinheiro, L. F. M. A., \& Leite, P. C. S. (2018). O Parque Moscoso como espaço-memória da cidade de Vitória. Vitória-ES, Brasil: Editora Ifes. Recuperado de https://educapes.capes.gov.br/handle/capes/552952.

Ruiz, L., Motta, L., Bruno, D., Demonte, F., \& Tufró, L. (2014). Producción de materiales de comunicación y educación popular. Buenos Aires: Departamento de Publicaciones de la Facultad de Derecho y Ciencias Sociales de la Universidad de Buenos Aires.

Vosgerau, D. S. R., \& Romanowski, J. P. (2014). Estudos de revisão: implicações conceituais e metodológicas. Revista Diálogo Educacional, 41, 165-189.

Rebeque, P. V., Osteman, F., \& Viseu, S. (2017). Os mestrados profissionais em ensino de ciências e matemática no Brasil: um tema pouco explorado na literatura. Revista brasileira de ensino de ciências e tecnocologia, 10(2), 1-21. Recuperado de https://periodicos.utfpr.edu.br/rbect/article/view/4386. 